\title{
ILL REGRESO DE LA HISTORIA O LA REFORMA DE LAS CUMBRES IBEROAMERICANAS
}

PABLO HISPÁN IGLESIAS DE USSEL

Doctor en Historia. Madrid 


\section{SUMARIO}

I. INTRODUCCIÓN. II. LA ESPECIFICIDAD DE LAS CUMBRES IBEROAMERICANAS. III. ¿ES UNA REALIDAD LA COMUNIDAd IBEROAMERICANA DE NACIONES? EL PASO DEL IDEALISMO AL REALISMO. 


\title{
EL REGRESO DE LA HISTORIA O LA REFORMA DE LAS CUMBRES IBEROAMERICANAS
}

\author{
POR \\ PABLO HISPÁN IGLESIAS DE USSEL \\ Doctor en Historia. Madrid
}

\section{INTRODUCCIÓN}

Parece un ejercicio de inactualidad, en medio de las presentes circunstancias internacionales, cuando todos los ojos miran hacia Oriente, volver a hacer un esfuerzo y tratar de poner de relieve la importancia que supuso que el 18 de julio de 1991 se reuniesen por primera vez en Guadalajara, México, los líderes de 19 naciones americanas, junto con los gobernantes de Portugal y España, y constituyesen un foro anual que ha pretendido llevar a cabo el proyecto de una Comunidad Iberoamericana de Naciones.

Aun asi, son muchas las circunstancias que asemejan el entorno de entonces con el que nos encontramos actualmente. Europa estaba en un compás de espera, todavía aturdida de los sucesos que sacudieron el Este del continente y concluyeron con la caída del muro de Berlín. Ese compás de espera, que se inició en el mes de noviembre de 1989, estaba preparándose para recibir un nuevo impulso, que llegaría en el mes de diciembre de 1991, en la localidad holandesa de Maastricht, y que dio nombre a un tratado que marcó un rumbo definitivo en la Unión.

Si la construcción europea vivía un momento fundamental ese mes de julio de 1991, la comunidad internacional vivía en unas cir- 
cunstancias semejantes a las actuales, ya que la I Guerra del Golfo acababa de llegar a un "alto el fuego" y el Consejo de Seguridad preparaba las resoluciones que garantizasen la estabilidad y la seguridad de la región.

De un modo indudable, los atentados del 11 de Septiembre de 2001 han marcado un punto de inflexión. El problema del terrorismo, que hasta el momento se había afrontado por las autoridades españolas como una lucha casi en solitario, adquiere una importancia primordial para el resto de naciones, y para Estados Unidos de modo singular. Al mismo tiempo, la Unión Europea vive un momento de profunda transformación en el que una Convención trata de actualizar los Tratados fundacionales y diez naciones llaman a su puerta, estando previstas para 2004 las primeras incorporaciones.

Junto a ello, el otro eje sobre el que se ha establecido la politica internacional española es el eje atlántico, es decir, la relación con América. En este contexto, la política de Cumbres ha sido una pieza importante.

Mucho se ha comentado sobre si el primer precedente, remoto, de las Cumbres lberoamericanas y del nacimiento de una Comunidad Iberoamericana de Naciones pudiera situarse en las Cortes de Cádiz, cuando acudieron diputados representantes de todos los virreinatos para conformar la primera Constitución liberal iberoamericana. Es indudable que este hecho, que cambió la historia del continente, puede ser un punto de partida dentro de la institucionalización política de un foro cuyas dos de sus principales características son el compromiso y la reafirmación de la democracia y las relaciones en un plano igualitario, sin preeminencias ni supremacías, tal y como se pone de manifiesto en la Declaración de Guadalajara:

"Reconocemos que este propósito de convergencia se sustenta, no sólo en un acervo cultural común sino, asimismo, en la riqueza de nuestros orígenes y en su expresión plural. Nuestra comunidad se asienta en la democracia, el respeto a los derechos humanos y en las libertades fundamentales" '.

Por esta razón, la Organización de Estados Iberoamericanos para la Educación, la Ciencia y la Cultura (1949), que indudablemente es un

1 Todas las referencias a declaraciones de las Cumbres Iberoamericanas pueden consultarse en la siguiente dirección de internet, que es la de la web de las cumbres iberoamericanas:

http://www.cip.cu/webcip/eventos/cumbre-ibero/cumbre_ibero.htm/ 
precedente, presenta numerosas anomalías como para ser tratada como un antecedente.

Ante estas circunstancias, es de justicia reconocer el acierto politico de los impulsores de la I Cumbre y de este nuevo tipo de diplomacia. Cuando se resquebrajaba el orden bipolar que había caracterizado el mundo desde la Conferencia de Yalta en 1945, un grupo de líderes se anticiparon y pusieron los cimientos a una nueva forma de multilateralismo que en nada se asemejaba a los precedentes que podían encarnar Gran Bretaña o Francia.

Aunque suene a tópico, es mucho lo que ha cambiado el entorno político Latinoamericano desde aquella primera Cumbre. De ser la paz y la transición a la democracia el primer punto en la agenda política de la región, ha pasado a ser la consolidación de la democracia y de sus instituciones el aspecto de interés más urgente. A pesar de ello, Cuba permanece como el último país en el que no existe la democracia y los derechos humanos son violados de modo permanente.

Incluso en el plano multilateral, muchos han sido los cambios operados desde entonces en América Latina; el reforzamiento del papel político de la Organización de Estados Americanos, la creciente importancia de las reuniones de los países ribereños del Pacífico, tanto asiáticos como americanos, y las Cumbres Unión Europea-América Latina y el Caribe. De la misma forma, las integraciones regionales -Mercosur, la Comunidad Andina, el Plan Puebla-Panamá- son ejemplos de nuevas formas de multilateralidad. La constitución del Área de Libre Comercio de las Américas supondrá de un modo indudable un impulso definitivo a la integración continental.

\section{LA ESPECIFICIDAD DE LAS CUMBRES IBEROAMERICANAS}

Tal y como afirma Celestino del Arenal ${ }^{2}$, desde que se pusiese en marcha la primera Cumbre han sido dos las posibilidades hacia las que se podía orientar. Por un lado, planteaba la formación de un espacio común lberoamericano, que actuase con voz propia en el escenario mundial y afirmase sus intereses comunes. La otra opción era la

2 Celestino del ArenAL, "De Guadalajara a Lima; las Cumbres Iberoamericanas, una realidad en marcha", en El sistema de Cumbres Iberoamericanas (coord. Laura Ruiz-Giménez y Tomás Mallo), Madrid, 2002, pág. 75. 
de limitarse a un mero voluntarismo declarativo y a la manifestación retórica de una posición común frente a diversos hechos.

Los impulsores del sistema de Cumbres trataron de conferir al foro un indudable papel político desde el primer instante. La propia Declaración de Guadalajara así lo señalaba en su primer párrafo:

"Con especial beneplácito nos hemos congregado, por primera vez en la historia, para examinar de forma conjunta los grandes retos que conforman nuestros países en un mundo en transformación. Nos proponemos, por ello, concertar la voluntad política de nuestros gobiernos para propiciar las soluciones que estos desafíos reclaman".

Esta indudable y firme voluntad política, que se había venido reafirmando en todas las declaraciones de todas las Cumbres era evidente que, precisamente en sus aspectos políticos, no ha pasado de su faceta voluntarista. Como ha señalado un de los principales comentaristas políticos latinoamericanos, Andrés Oppenheimer, el hecho de que dictadores como Fujimori o Castro pudiesen firmar sin problemas declaraciones que mostraban un compromiso inequívoco con los Derechos Humanos y la democracia, especialmente las de Guadalajara o la de Viña del Mar de 1996, fue uno de los exponentes más claros que llevaron al sistema de Cumbres al papel de una simple conferencia anual de Jefes de Estado y de Gobierno, en la que lo interesante no era la articulación de una Comunidad Iberoamericana, sino la posibilidad de sostener un buen número de encuentros bilaterales en un corto espacio de tiempo o la de asegurar el apoyo de la comunidad iberoamericana a candidaturas de personalidades de este ámbito a organismos internacionales - no sin dificultades por parte de España y Portugal por sus compromiso europeos-.

Junto a este hecho, se ha venido observando un carácter asimétrico en el impulso de la construcción de la Comunidad lberoamericana. Mientras que la implicación española ha sido muy grande, y no circunscrita exclusivamente al nivel gubernamental, para los dirigentes latinoamericanos ha ocupado un lugar secundario. En cierto modo por la simultaneidad con un instrumento como la Organización de Estados Americanos, con unas competencias claramente definidas y un papel relevante como institución.

Por estas razones, el único aspecto que ha tenido una cierta continuidad y éxito relativo ha sido el referido a la cooperación, a la que en un principio se pretendió conferir un carácter descentralizado y que en la Cumbre de La Habana en 1999, se centralizó finalmente en la Secretaría de Cooperación Iberoamericana (SECIB) con sede en 
Madrid, y en la que se puso al frente, con un mandato de 4 años, al mexicano Jorge Alberto Lozoya.

Desde que se pusiese en marcha en el año 2000, ha tratado de coordinar y relacionar estrechamente a las diversas instancias gubernamentales, instituciones públicas y privadas, empresas y demás organizaciones vinculadas con la construcción iberoamericana.

En este ámbito se han venido dando pasos de singular importancia, en lo referido a la cooperación, por medio de programas de formación de funcionarios de la Administración Pública en alguna de las seis sedes académicas de referencia. También en el ámbito audiovisual y de la comunicación, a través del apoyo a la construcción de un espacio común Iberoamericano (IBERMEDIA) o de los programas de Televisión Educativa (TEIB) se han dado pasos cuantificables, así como proyectos de alfabetización, de formación y capacitación profesional. Los Archivos, bibliotecas, juventud, cooperación científica y tecnológica y de apoyo a la Pequeña y Mediana Empresa y nuevas tecnologías han sido otros ámbitos donde los progresos han sido evidentes.

Como se puede ver a la hora de enumerar los programas en funcionamiento, el sistema de Cumbres, que pretendió ser una articulación política de lo que es una evidente sintonía y afinidad cultural, ha sido exitoso hasta el momento, precisamente, en su dimensión cultural. Este esfuerzo quizás no hubiera podido concretarse sin la organización de una red de Coordinadores Nacionales y de Responsables de Cooperación.

Junto a ello, el mecanismo de Cumbres ha creado una cierta inercia que ha motivado la aparición, junto con la conferencia anual de Jefes de Estado, de una serie de reuniones y foros transversales tanto de carácter político, como son las conferencias sectoriales de ministros, como de otros estamentos de la sociedad civil: notarios, Tribunales de Justicia, jóvenes empresarios, artistas, etc.

Estas circunstancias han hecho aflorar las contradicciones que persisten y que dificultan la construcción de una verdadera Comunidad Iberoamericana. Así por ejemplo, el compromiso de los rectores para coordinar los planes de estudio universitarios es estéril sin el impulso y respuesta política por parte de los Gobiernos para establecer un Espacio Educativo Iberoamericano, un objetivo que es dificultado por las claras asimetrías que existen en este ámbito. 


\section{III. ¿ES UNA REALIDAD LA COMUNIDAD IBEROAMERICANA DE NACIONES? EL PASO DEL IDEALISMO AL REALISMO}

Está claro que, no sin dificultades, han sido muchos los progresos en todos los ámbitos y las contradicciones que han ido aflorando desde aquella primera reunión de julio de 1991.

El propio hecho de que, en España, apenas se hayan publicado trabajos sobre el sistema de cumbres es una muestra de un cierto fracaso o reticencia a la posibilidad de una verdadera articulación política de la Comunidad Iberoamericana, que si existe en un ámbito como el universitario ${ }^{3}$. Es por ello que la mayor, permanente y estable implicación de otros sectores se hace urgente.

El seguimiento de las Cumbres, que en la prensa española ha sido desigual ${ }^{4}$, se ha centrado en ocasiones en anécdotas especialmente centradas en el papel y actuaciones de Fidel Castro. Una de las propuestas que se han lanzado para evitar esto ha sido la posibilidad de llevar una agenda previa a las reuniones, lo que evitaría el ejercicio de la retórica y centraría las discusiones y reflexiones.

El hecho de que en España siempre se observase con un cierto punto de vista narcisista y de autocomplacencia y no en plano de igualdad, como es la verdadera naturaleza de este proyecto de Comunidad, al mismo tiempo que se constataba la asimetría de la implicación española y el escepticismo de los países americanos, unido al referido estancamiento del papel político de las Cumbres, llevaron a que, desgraciadamente una vez más, el Presidente español, José María Aznar, en el marco de la XII Cumbre, en Bávaro, República Dominicana, propusiese que el saliente Presidente de Brasil, Fernando Henrique Cardoso, formase un grupo de trabajo para reflexionar sobre los aspectos anteriormente referidos $y$ que presente medidas $y$ propuestas concretas y unas conclusiones en el marco de la XIII Cumbre, que tendrá lugar en Bolivia en el presente año 2003, con el objeto de incrementar la cohesión interna y de que la Comunidad, en cuanto tal, tenga una mayor presencia internacional.

3 Los principales son el coordinado por Francisco Rojas Aravena (ed.), Las cumbres iberoamericanas. Una mirada global, Flacso-Chile / Editorial Nueva Sociedad, Caracas, 2000; y el coordinado por Laura Ruiz-GIMÉNEZ y Tomás MALLo, El sistema de Cumbres Iberoamericanas, op. cit., Madrid, 2002.

4 Guadalupe RUIZ-GIMÉnEZ, Las Cumbres y los ciudadanos; imágenes en la prensa española de la Comunidad Iberoamericana de Naciones, pág. 84. 
Entre otros puntos a considerar estaría la creación de una secretaría permanente Iberoamericana y el incremento de la flexibilidad del mecanismo de cooperación.

Siendo importantes estos aspectos, creo que si también se lograse un sistema real de condena a aquellos países iberoamericanos que estuviesen violando los derechos humanos y se estableciese la posibilidad de una temporal exclusión de sus dirigentes, estaría dotándose a la Comunidad de un mayor papel político. Junto a esto, la oportunidad de establecer grupos de coordinación dentro del marco de la Cumbre, para intervenir en la ayuda de países en quiebra política, como es el caso actual de Venezuela o Bolivia, sería otro aspecto positivo.

Dentro de la labor de Cardoso deberían estar la propuestas concretas para incrementar la implicación, el protagonismo y la presencia de los principales países latinoamericanos (Brasil, México, Argentina, Chile,...); sin ellos, el proyecto no pasa de ser un mera aspiración ibérica.

Junto a esto, es necesario que entre los compromisos de cooperación se incluyese de un modo firme la lucha contra el terrorismo. Aún existen ejemplos, desgraciadamente, que entienden que el cálculo político y el interés nacional puede regatear la cooperación en éste ámbito. Sin el apoyo resuelto de la comunidad Iberoamericana, Colombia o España no podrán vencer a esa lacra.

A pesar de todo, es indudable que después de doce años los progresos han sido abundantes y que el sistema de Cumbres es una realidad. Aún así, es conveniente no olvidar que éste no es un fin en sí mismo, es un medio para construir una verdadera Comunidad Iberoamericana.

Son muchos los aspectos que es necesario reformar e impulsar, pero es justo reconocer que, en cierto modo, esta Comunidad es ya una realidad, cambiante y pluriforme, pero en marcha. El hecho de que otros países hayan solicitado su vinculación a la misma, como son Belice y Puerto Rico, es ya un motivo de complacencia y satisfacción.

Ante estos hechos, las Cumbres, que nacieron cuando se decía que la historia había muerto, parece que, al igual que ésta, permanecen muy vivas y con muchos proyectos por delante, transformándose, poco a poco en el sueño del uruguayo José Enrique Rodó, que escribía en 1900 en su conocida obra Ariel: 
"Ariel se lanzará desde allí a la conquista de las almas. Yo lo veo, en el porvenir, sonriéndoos con gratitud, desde lo alto, al sumergirse la sombra de vuestro espíritu. Yo creo en vuestra voluntad, en vuestro esfuerzo; y aún más en los de aquellos a quienes daréis la vida y transmitiréis vuestra obra. Yo suelo embriagarme con el sueño del día en que las cosas reales harán pensar en que la Cordillera que se yergue sobre el suelo de América ha sido tallada para ser el pedestal de esta estatua [...].

[...] el Crucero, cuyos brazos abiertos se tienden sobre el suelo de América como para defender una última esperanza...".

Quizás, en el mundo de la globalización, la Comunidad Iberoamericana de Naciones es el nuevo nombre de esta esperanza. 